\title{
植物生长调节剂对油菜生长及冻害后光合作用和产量的调控效应
}

\author{
马 霓 刘 丹 张春雷* 李 俊 李光明
}

中国农业科学院油料作物研究所, 湖北武汉 430062

摘 要: 在油菜始花期喷施不同浓度的脱落酸(ABA)和油菜素内酯(BR), 分析其对油菜叶片光合速率和产量的影响; 2008 年 1 月低温冰冻天气之后, 采用优化浓度的 $\mathrm{ABA}$ 和 $\mathrm{BR}$ 处理, 测定油菜叶片的气体交换参数和叶绿素苂光参数, 比较角果形态变化规律及产量构成因素。主要结果如下: 与对照 $(\mathrm{CK})$ 相比, 喷施 $76 \times 10^{-6} \mathrm{~mol} \mathrm{~L}^{-1} \mathrm{ABA}$ 和 $1 \times 10^{-6} \mathrm{~mol}$ $\mathrm{L}^{-1} \mathrm{BR}$ 能延缓叶片光合速率的下降, 冻害后喷施该浓度 $\mathrm{ABA}$ 和 $\mathrm{BR}$ 提高了叶片净光合速率 $\left(P_{\mathrm{n}}\right)$ 、光饱和点 $(\mathrm{LSP})$ 、气 孔导度 $\left(G_{\mathrm{s}}\right)$ 、胞间 $\mathrm{CO}_{2}$ 浓度 $\left(C_{\mathrm{i}}\right)$ 与蒸腾速率 $\left(T_{\mathrm{r}}\right)$; 最大光化学效率 $\left(F_{\mathrm{v}} / F_{\mathrm{m}}\right)$ 、光系统 II 量子产量 $\left(\Phi_{\mathrm{PSII}}\right)$ 与光化学猝灭系数 $\left(q_{\mathrm{P}}\right)$ 均升高, 叶绿素初始苂光 $\left(F_{\mathrm{o}}\right)$ 和非光化学猝灭系数 $(N P Q)$ 降低, $\mathrm{ABA}$ 和 $\mathrm{BR}$ 处理还提高叶片中叶绿素含量及可溶性 蛋白的含量; 角果面积增大, BR 处理后单株角果数、每角粒数、千粒重及产量都比对照增加, ABA 处理可增加角粒 数和千粒重, 进而提高油菜的产量。总之, $76 \times 10^{-6} \mathrm{~mol} \mathrm{~L}^{-1} \mathrm{ABA}$ 和 $1 \times 10^{-6} \mathrm{~mol} \mathrm{~L}{ }^{-1} \mathrm{BR}$ 能促进油菜生长并有效缓解冻害 对油菜的影响。

关键词：甘蓝型油菜；冻害；植物生长调节剂；光合作用；产量

\section{Regulation Effects of Exogenous Hormones on Growth and Photosynthesis and Yield of Rapeseed (Brassica napus L.) after Frozen}

\author{
MA Ni, LIU Dan, ZHANG Chun-Lei ${ }^{*}$, LI Jun, and LI Guang-Ming \\ Oil Crops Research Institute, Chinese Academy of Agricultural Sciences, Wuhan 430062, China
}

\begin{abstract}
Different concentrations of exogenous hormones were applied on rapeseed at the initial blossoming stage. The net photosynthetic rate $\left(P_{\mathrm{n}}\right)$ and yield were investigated. In January 2008, a heavy snow and low temperature for a period destroyed crops including winter rape. In this experiments, exogenous hormones ABA and BR with optimal concentrations were applied on the rapeseed (Brassica napus L.) plants after the frozen from the worst weather. The gas exchange parameters and chlorophyll fluorescence characteristics of leaves as well as the regularity of pod size changes and yield components were determined. The results were as follows: $\mathrm{ABA}\left(76 \times 10^{-6} \mathrm{~mol} \mathrm{~L}^{-1}\right)$ and $\mathrm{BR}\left(1 \times 10^{-6} \mathrm{~mol} \mathrm{~L}^{-1}\right)$ could delay the decreasing of net photosynthetic rate $\left(P_{\mathrm{n}}\right)$ in short petiole leaves. The $P_{\mathrm{n}}$, stomatal conductance $\left(G_{\mathrm{s}}\right)$, intercellular $\mathrm{CO}_{2}$ concentration $\left(C_{\mathrm{i}}\right)$, transpiration rate $\left(T_{\mathrm{r}}\right)$ and photosynthetic saturated light intensity (LSP) were increased after exogenous hormones treatment. ABA and BR treatments also caused a significant increase in the maximum photochemical efficiency of photosystem II $\left(F_{\mathrm{v}} / F_{\mathrm{m}}\right)$, the quantum yield of electron transport $\left(\Phi_{\mathrm{PSII}}\right)$, the photochemical quenching co-efficient $\left(q_{\mathrm{P}}\right)$, Chl content and soluble protein content. These changes were accompanied by the decline in both minimal fluorescence $\left(F_{0}\right)$ and non-photochemical quenching co-efficient $(N P Q)$. The pod surface areas per pod were increased. The number of the first branches per plant and seeds per pod and 1000-seed weight were raised, resulting in improvement of yield after BR treatment. As to the plants after ABA treatment, the high yield was mainly attributed to the increasing of seeds per pod and 1000-seed weight. In conclusion, ABA $\left(76 \times 10^{-6} \mathrm{~mol} \mathrm{~L}^{-1}\right)$ and $\mathrm{BR}\left(1 \times 10^{-6} \mathrm{~mol} \mathrm{~L}{ }^{-1}\right)$ treatments are effective on promoting the growth and relieving the negative effects of frozen on rapeseed.
\end{abstract}

Keywords: Rapeseed (B. napus L.); Frozen; Exogenous hormone; Photosynthesis; Yield

植株正常生长所需的有机物是通过光合作用提 供的 ${ }^{[1]}$ 。作物在生长过程中经常会遭遇冷、热、旱、 涝、盐碱、大气污染等不良环境因素的影响, 冻害
是影响和限制农作物生产的主要因素之一。当遭受 冻害胁迫时, 植株脱水机械变形, 细胞损伤, 导致 细胞膜结构紊乱 ${ }^{[2]}$, 解冻时酶类功能活性明显下降,

\footnotetext{
本研究由国家“ 十一五” 科技支撑计划重点项目课题(2006BAD21B03)和中国农业科学院油料作物研究所所长基金(SZ200803-07)资助。

*通讯作者(Corresponding author): 张春雷, E-mail: clzhang@vip.sina.com; Tel: 027-86739796

第一作者联系方式: E-mail: manihuihui@yahoo.com.cn

Received (收稿日期): 2008-10-23; Accepted (接受日期): 2009-03-20.
} 
代谢过程被破坏，受伤组织死亡 $亡^{[3]}$ 。冰冻胁迫会引 起叶绿体功能障碍影响叶绿体基质内生物合成, 降 低光合碳代谢中利用 ATP 和 NADPH 的能力 ${ }^{[4]}$, 影 响光合电子传递和光合磷酸化以及暗反应有关酶十 系, 增加冷敏感植物和抗冷植物发生光抑制的可能 性 ${ }^{[5]}$ 以及对光合作用反应中心的损伤 ${ }^{[6]}$ 。叶绿素荧光 动力学技术对测定叶片光合作用中光系统光能的吸 收、传递、耗散、分配等具有独特的作用, 可以直 接反映植物对环境胁迫的耐受能力及胁迫条件下的 生理变化。通过测定苂光参数的日变化可以得知植 物一天中 $N P Q$ 的变化、电子传递速率变化、光化学 量子效率变化和光抑制的程度 ${ }^{[7]}$ 。

气候异常对全球农业发展带来了严重影响, 科 技人员在深入探讨植物遇到气温突变的应激机理的 同时, 考虑采取一些保护措施降低农业生产的损 失。植物生长调节剂能有效地影响和控制植物的生 长发育及对环境的适应性。已有的研究表明植物生 长调节剂能提高作物的产量和品质 ${ }^{[8-10]}$, 增强作物 抗寒的能力, 促进幼苗在低温下生长, 叶绿素含量 明显增加, 抗氧化酶活性上升 ${ }^{[11-13]}$, 关于植物生长 调节剂对低温下作物光合作用及产量影响的研究并 不多见。油菜是我国主要的油料作物, 在生长期间 常常会遭遇到低温灾害, 对其进行抗灾减灾技术研 究是确保我国油料安全生产的重大需求。2008 年 1 月, 我国长江流域湖北、湖南、江西、安徽、江苏、 浙江、上海、贵州、云南、广西等省区经历了长达 20 多天的大面积持续雨雪冰冻天气, 油菜受灾面积 占全国冬油菜面积 $77.8 \%$, 平均冻害指数为 $33.9^{[14]}$ 。 本试验研究不同浓度的植物生长调节剂对油菜生长 的促进或抑制作用; 并在冰冻天气结束后, 喷施优化 浓度的 $\mathrm{ABA}$ 和 $\mathrm{BR}$, 探索植物生长调节剂对油菜短柄 叶气体交换参数与叶绿素苂光参数的影响, 以及对 可溶性蛋白和叶绿素含量动态的调节作用, 比较角 果形态的变化规律和产量构成因素, 以期为制定油 菜冻害防治措施，抗灾减灾提供科学依据。

\section{1 材料与方法}

试验材料为甘蓝型油菜 (Brassica napus L.)品种 中双 9 号, 试验于 2006-2008 年在中国农科院油料 所内进行。

\section{1 盆栽试验}

在油料所网室内, 播种前取土过篮, 拌杀菌剂, 掺入适量沙子和蛭石, 每公斤混合土添加 $0.5 \mathrm{~g}$ 纯
$\mathrm{N}, 0.15 \mathrm{~g} \mathrm{P}_{2} \mathrm{O}_{5}, 0.2 \mathrm{~g} \mathrm{~K}_{2} \mathrm{O}$, 种子经 $1 \%$ 氯化永消毒, 在恒温培养箱中 $35^{\circ} \mathrm{C}$ 催芽 $24 \mathrm{~h}$ 至露白, 于 2006 年 9 月 26 日播于钵内, 生长至三叶期每钵留 1 株壮苗, 精细管理。油菜始花期对植株进行脱落酸 (ABA, $38 \times 10^{-6} \mathrm{~mol} \mathrm{~L}^{-1} 、 76 \times 10^{-6} \mathrm{~mol} \mathrm{~L}^{-1}$ 和 $1 \times 10^{-4} \mathrm{~mol} \mathrm{~L}^{-1}$, Sigma USA), 油菜素内酯 $\left(\mathrm{BR}, 1 \times 10^{-6} \mathrm{~mol} \mathrm{~L}^{-1}\right.$ 、 $2 \times 10^{-6} \mathrm{~mol} \mathrm{~L}^{-1}$ 和 $1 \times 10^{-5} \mathrm{~mol} \mathrm{~L}^{-1}$ )和清水(对照)处理。 于晴朗无风的下午 3:00 5:00 整株喷施，每处理至少 3 盆, 使植株叶片全湿。

第二年于 9 月 23 日播种，自 2008 年 1 月 11 日 起, 连续一个月 $-3.0 \sim 0.5^{\circ} \mathrm{C}$ 低温雨雪天气，极端低温 达 $-8.5 \sim-11.5^{\circ} \mathrm{C}$ (武汉中心气象台数据资料)。雨雪 天气结束后, 参照 $2006 \square 2007$ 年试验结果及杨建昌

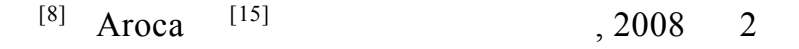
25 日用脱落酸 $\left(A B A, 76 \times 10^{-6} \mathrm{~mol} \mathrm{~L}^{-1}\right.$, Sigma USA); 油菜素内酯(BR, $1 \times 10^{-6} \mathrm{~mol} \mathrm{~L}^{-1}$ )和清水(对照)处理 油菜植株, 使植株叶片全湿, 3 次重复。

\section{2 田间试验}

在油料所试验地进行, 土壤肥力中等。设 3 种 处理, 3 次重复, 随机区组设计, 小区面积 $20 \mathrm{~m}^{2}$, 施 肥水平为 $180 \mathrm{~kg} \mathrm{hm}^{-2}$ 纯 $\mathrm{N}, 90 \mathrm{~kg} \mathrm{hm}^{-2} \mathrm{P}_{2} \mathrm{O}_{5}, 180 \mathrm{~kg}$ $\mathrm{hm}^{-2} \mathrm{~K}_{2} \mathrm{O}$, 按照 5:3:2 的比例分基肥、苗肥和腊肥 施氮, 磷肥和钾肥全部作基肥施用, 播种前施嗍肥 $22.5 \mathrm{~kg} \mathrm{hm}^{-2}$ 。分别于 2006 年 9 月 26 日和 2007 年 9 月 23 日播种, 每公顷 19.5 万株, 条播, 行距 $33 \mathrm{~cm}$ 。

2007 年 3 月 6 日油菜始花期喷施 ABA 和 BR(浓 度与盆栽相同), 于晴朗无风的下午 3:00 5:00 整株 喷施，以清水为对照; 2008 年 1 月低温雨雪天气结 束后, 2 月 25 日用上一年优化浓度的 ABA 和 BR(浓 度与盆栽相同)处理油菜植株, 开花后每个小区选植 株生长正常，长势一致的单株挂牌标记。

\section{3 叶片光合速率测定}

2007 年 3 月 6 日喷施不同浓度 $\mathrm{ABA}$ 和 $\mathrm{BR}$ 后, 第 2 天 9:00 11:00 用便携式光合作用测定系统 (LI-6400 USA)测定主茎上离长柄叶最近的第 1 片短 柄叶的光合速率 $\left(P_{\mathrm{n}}\right)$, 每 $5 \mathrm{~d}$ 测定一次, 间隔 2 3 min 采集一次数据, 3 次重复。

\section{4 叶片光响应曲线测定}

油菜冻害后喷施外源 $\mathrm{ABA} 、 \mathrm{BR}$ 和清水处理, 第 2 天 9:00 11:00 分别测定盆栽材料主茎上离长柄叶 最近的第 1 片短柄叶的光合速率 $\left(P_{\mathrm{n}}\right)$ 、气孔导度 $\left(G_{\mathrm{s}}\right)$ 、 胞间二氧化碳浓度 $\left(C_{\mathrm{i}}\right)$ 、蒸腾速率 $\left(T_{\mathrm{r}}\right)$ 。叶室 $\mathrm{CO}_{2}$ 浓 度为 $400 \mu \mathrm{mol} \mathrm{mol}^{-1}$, 空气流速为 $500 \mu \mathrm{mol} \mathrm{s}{ }^{-1}$, 设定 光强梯度为 $1500 、 1200 、 1000 、 800 、 500 、 200$ 、 
100、 $0 \mu \mathrm{mol} \mathrm{m} \mathrm{s}^{-1}$, 叶片温度 $25^{\circ} \mathrm{C}$ 。每个光强下间 隔 2 3 min 采集一次数据, 3 次重复。

\section{5 叶绿素苂光参数测定}

冻害后采用 LI-6400 菼光叶室, 于 3 个不同处 理结束的第 3 天 9:00 11:00 分别测定盆栽材料的 气体交换和叶绿素苂光参数, 每处理测定 3 株, 取 平均值。测定暗适应苂光参数时, 先将叶片放在暗 适应夹中适应 $30 \mathrm{~min}$, 用弱测量光测定初始苂光

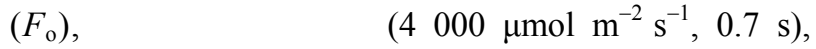
测定最大荧光 $\left(F_{\mathrm{m}}\right)$; 再将样品置于持续的光化学 活性光 $\left(1000 \mu \mathrm{mol} \mathrm{m} \mathrm{m}^{-2} \mathrm{~s}^{-1}\right)$ 下照射 $0.5 \mathrm{~h}$, 得到稳态 苂光 $\left(F_{\mathrm{s}}\right)$, 再用强饱和光 $\left(4000 \mu \mathrm{mol} \mathrm{m} \mathrm{m}^{-2} \mathrm{~s}^{-1}, 0.7 \mathrm{~s}\right)$ 照射, 测定光下最大苂光 $\left(F_{\mathrm{m}}{ }^{\prime}\right)$, 关闭光化学活性 光, 施加远红光以测量光适应的 $F_{\mathrm{o}}{ }^{\prime}$ 。光系统 $\mathrm{II}(\mathrm{PSII})$ 最大光化学量子效率 $\left(F_{\mathrm{v}} / F_{\mathrm{m}}\right)=\left(F_{\mathrm{m}}-F_{\mathrm{o}}\right) / F_{\mathrm{m}}$; PSII 量子效率 $\left(\Phi_{\mathrm{PSII}}\right)=\left(F_{\mathrm{m}}{ }^{\prime}-F_{\mathrm{s}}{ }^{\prime}\right) / F_{\mathrm{m}}{ }^{\prime}$; 光化学猝灭 系数 $\left(q_{\mathrm{P}}\right)=\left(F_{\mathrm{m}}{ }^{\prime}-F_{\mathrm{s}}\right) /\left(F_{\mathrm{m}}{ }^{\prime}-F_{\mathrm{o}}\right)$; 非光化学猝灭系数 $(N P Q)=\left(F_{\mathrm{m}}-F_{\mathrm{m}}{ }^{\prime}\right) / F_{\mathrm{m}}{ }^{\prime[16]}$ 。

1.6 叶绿素含量和可溶性蛋白含量的测定

油菜冻害后，在植物生长调节剂处理结束的第 1 、 3、5 和 7 天测定叶绿素含量和可溶性蛋白含量。利用 SPAD-502 叶绿素测定仪, 在距离叶柄 1/3 处分别测定 盆栽材料第一片短柄叶的叶绿素含量, 3 次重复。

参照王学奎 ${ }^{[17]}$ 的方法测可溶性蛋白含量, 用考 马斯亮蓝 G-250 染色, 以牛血清蛋白作标准曲线, 测定 $595 \mathrm{~nm}$ 处的吸光值。

\section{7 角果形态变化和经济性状考查}

田间材料于 2007 年 3 月 18 日和 2008 年 3 月 21 日进入盛花期, 每隔 $5 \mathrm{~d}$ 定期从挂牌主茎和一次 分枝上随机取 20 个角果用游标卡尺测量角果的长 度和最大宽度, 数每角果粒数, 按 Clarke ${ }^{[18]}$ 公式计 算角果皮面积, 取平均值。

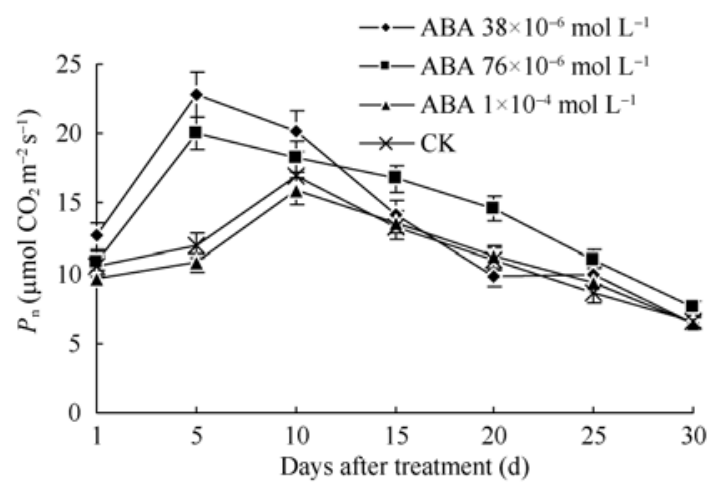

田间油菜植株成熟期取样。每小区连续取 10 株, 按照标准田间区试考种方法考查产量及产量 构成因素。

\section{8 统计分析}

利用 SPSS9.0 统计软件进行数据分析, 并作方 差分析(ANOVA), 所有数据通过最小显著性检验 $(L S D)$, 最低显著性标准 0.05 。

\section{2 结果与分析}

\section{1 叶片光合速率}

从图 1 可以看出, 不同浓度的 $\mathrm{ABA}$ 和 $\mathrm{BR}$ 对油菜 叶片净光合速率 $\left(P_{\mathrm{n}}\right)$ 都有一定的影响。低浓度 $\mathrm{ABA}$ $\left(38 \times 10^{-6} \mathrm{~mol} \mathrm{~L}^{-1}\right)$ 处理后 $P_{\mathrm{n}}$ 值在第 5 天达到所有处理 中的最高值 $22.9 \mu \mathrm{mol} \mathrm{m}{ }^{-2} \mathrm{~s}^{-1}$, 比对照(CK)增加 $90.5 \%$, 但随后下降较快; 中浓度 ABA $\left(76 \times 10^{-6} \mathrm{~mol} \mathrm{~L} \mathrm{~L}^{-1}\right)$ 处理 后第 5 天 $P_{\mathrm{n}}$ 值也迅速上升，比对照增加 $66.7 \%$ ，虽然 其后也下降, 但趋势较平缓, 并一直保持较高值; 喷 施高浓度 $\mathrm{ABA}\left(1 \times 10^{-4} \mathrm{~mol} \mathrm{~L}^{-1}\right)$ 以后，可能由于 $\mathrm{ABA}$ 的抑制作用导致气孔关闭，光合速率出现下降，处理 后 $10 \mathrm{~d}, P_{\mathrm{n}}$ 值一直低于对照, $15 \mathrm{~d}$ 以后和对照表现出相 同的下降趋势。 $1 \times 10^{-6} \mathrm{~mol} \mathrm{~L}^{-1} \mathrm{BR}$ 和 $2 \times 10^{-6} \mathrm{~mol} \mathrm{~L}^{-1} \mathrm{BR}$ 处理后, 光合速率比对照高, 且最高值出现的时期在 处理后 $10 \mathrm{~d}$ 左右, 随后 $P_{\mathrm{n}}$ 值缓慢下降, 但 $1 \times 10^{-5} \mathrm{~mol}$ $\mathrm{L}^{-1} \mathrm{BR}$ 处理使油菜光合速率降低。

\section{2 叶片气体交换参数}

2008 年 1 月低温冻害以后, 喷施 ABA $\left(76 \times 10^{-6}\right.$ $\left.\mathrm{mol} \mathrm{L}{ }^{-1}\right)$ 和 $\mathrm{BR}\left(1 \times 10^{-6} \mathrm{~mol} \mathrm{~L}^{-1}\right)$ 。从图 2 可以看出, 油 菜叶片 $P_{\mathrm{n}}$ 值均明显高于对照 $(\mathrm{CK})$, 喷施 $\mathrm{ABA}$ 后 $P_{\mathrm{n}}$ 为对照的两倍, 根据 Farquhar 模型拟合 ${ }^{[19]}$, 当光强 达到 $1100 \mu \mathrm{mol} \mathrm{m}{ }^{-2} \mathrm{~s}^{-1}$ 时光合速率不再升高, $P_{\mathrm{n}}$ 值 为 $20.7 \mu \mathrm{mol} \mathrm{m} \mathrm{m}^{-2} \mathrm{~s}^{-1}$ 时的光强为叶片的光饱和点, 采用同样的方法得到 BR 和对照的光饱和点分别为

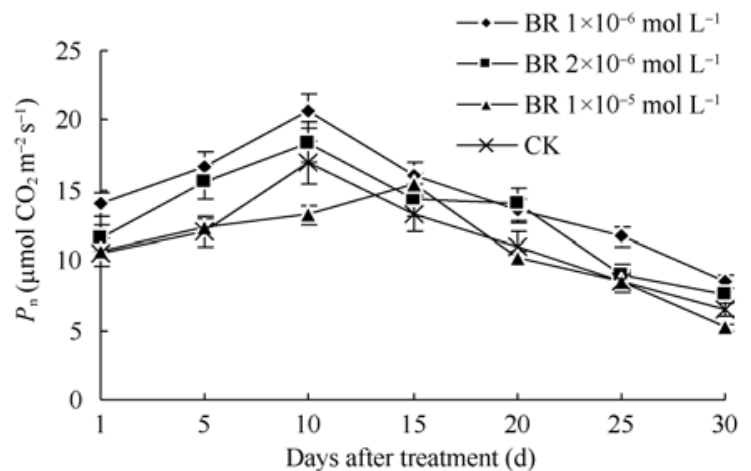

图 1 ABA 和 BR 处理对油菜短柄叶光合速率的影响 $(2006-2007)$

Fig. 1 Effects of ABA and BR treatments on net photosynthetic rate in short petiole leaves of rapeseed(2006-2007) 
$1000 \mu \mathrm{mol} \mathrm{m} \mathrm{m}^{-2} \mathrm{~s}^{-1}$ 和 $950 \mu \mathrm{mol} \mathrm{m} \mathrm{m}^{-2}$; 植物生长调 节剂处理后气孔导度高于对照, 其中 ABA 处理后气 孔导度由最初的 $0.151 \mathrm{~mol} \mathrm{~m}^{-2} \mathrm{~s}^{-1}$ 迅速下降至 0.098 $\mathrm{mol} \mathrm{m} \mathrm{m}^{-2} \mathrm{~s}^{-1}$, 然后又快速上升, 这可能是气孔对生长 调节剂的应激反应及随后的适应过程; 光合有效辐 射增强, 胞间 $\mathrm{CO}_{2}$ 浓度 $\left(C_{\mathrm{i}}\right)$ 不断降低, 表明叶片光合 作用增强, 光合作用消耗的 $\mathrm{CO}_{2}$ 量大于呼吸作用产 生的 $\mathrm{CO}_{2}$ 的数量, 对照的胞间 $\mathrm{CO}_{2}$ 浓度下降幅度最 大, 光照强度高于 $500 \mu \mathrm{mol} \mathrm{m} \mathrm{m}^{-2} \mathrm{~s}^{-1}$ 时, $C_{\mathrm{i}}$ 值保持稳定; 喷施生长调节剂后蒸腾速率变化曲线和气孔导度的 变化趋势相似。

\section{3 叶绿素苂光参数}

从表 1 可以看出, 冻害后用 $\mathrm{ABA} 、 \mathrm{BR}$ 处理 $F_{\mathrm{o}}$ 值和对照相比降幅较大, 达到显著和极显著水平, PSII 最大光化学量子产量 $\left(F_{\mathrm{v}} / F_{\mathrm{m}}\right)$ 值常用来度量植物
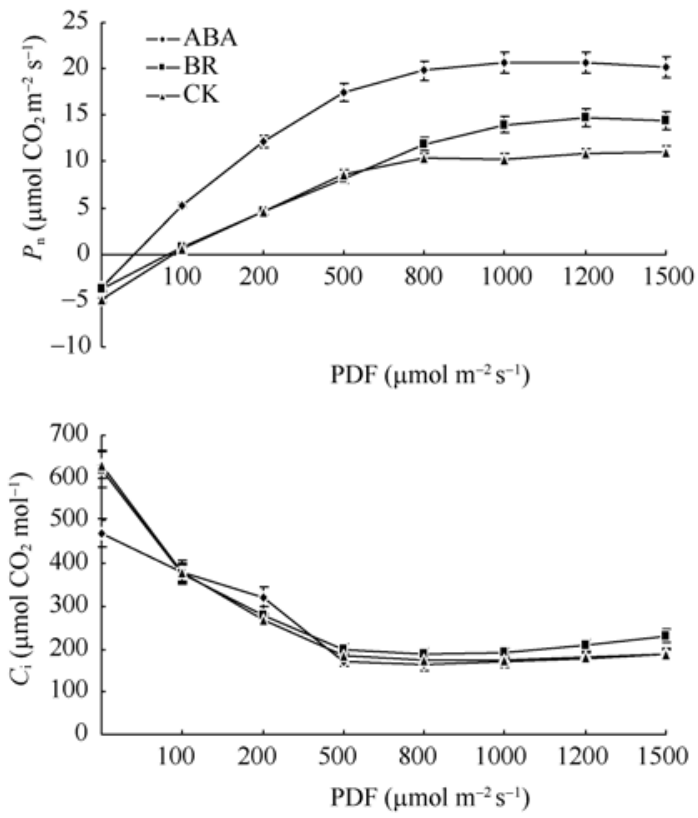

叶片 PSII 原初光能转换效率, 反映 PSII 利用光能的

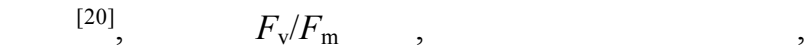
$\mathrm{ABA}$ 处理后 $F_{\mathrm{v}} / F_{\mathrm{m}}$ 最高, 比对照显著增加。 $\Phi_{\mathrm{PSII}}$ 是作 用光存在时 PSII 的实际量子效率，表示进入 PSII 的 光能中用于光化学反应的光能所占比例，从表 1 同样 可以看出 $\mathrm{ABA} 、 \mathrm{BR}$ 处理后量子产量 $\left(\Phi_{\mathrm{PSII}}\right)$ 的升高都 达到极显著水平。 $q_{\mathrm{P}}$ 代表叶绿素苂光的光化学猝灭系 数, 被认为是光适应状态下 PSII 进行光化学反应的 能力, 即 PSII 反应中心开放的程度 ${ }^{[21]}$, 本试验结果 显示外源 $\mathrm{ABA}$ 和 $\mathrm{BR}$ 处理后 $q_{\mathrm{P}}$ 值比对照显著增大, 说明叶片 PSII 反应中心光能转换效率和原初光能捕 获效率增强。非光化学猝灭系数 $(N P Q)$ 反映了 PSII 天线色素吸收的光能不能用于光化学电子传递而以 热的形式耗散掉的部分, $\mathrm{ABA}$ 和 $\mathrm{BR}$ 处理后 $N P Q$ 值 都有不同程度的降低, $\mathrm{ABA}$ 处理后 $N P Q$ 值显著降低。
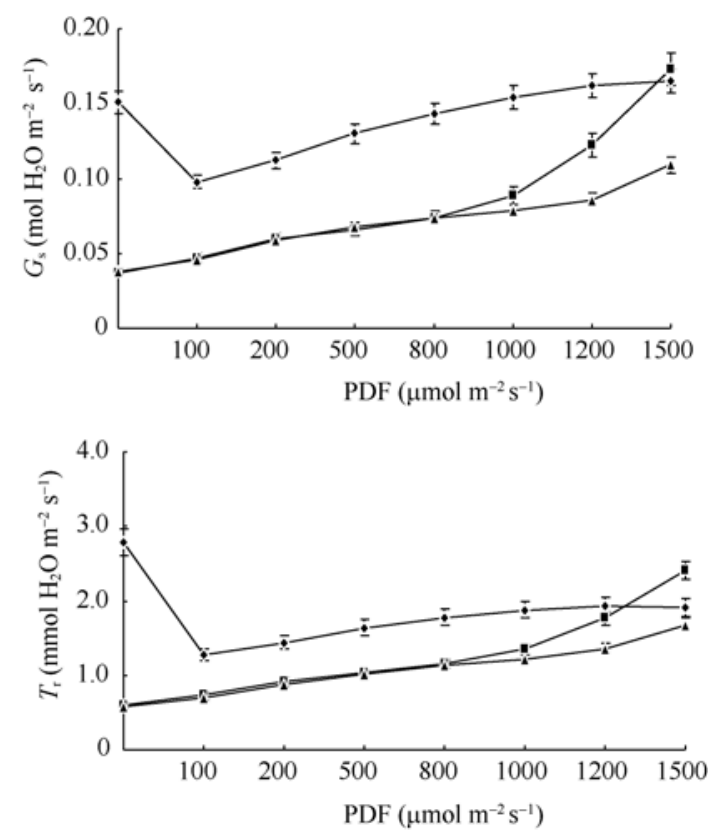

图 2 冻害胁迫后 ABA 和 BR 处理对油菜短柄叶气体交换参数的影响 $(2007-2008)$

Fig. 2 Effects of ABA and BR treatments on gas exchange parameters in short petiole leaves of rapeseed after frozen (2007-2008)

表 1 ABA 和 BR 处理后短柄叶叶绿素荧光参数的变化(2007-2008)

Table 1 Changes of Chlorophyll fluorescence parameters in short petiole leaves of rapeseed after ABA and BR treatments (2007-2008)

\begin{tabular}{ccccc}
\hline $\begin{array}{c}\text { 处理 } \\
\text { Treatment }\end{array}$ & $F_{\mathrm{o}}$ & $F_{\mathrm{v}} / F_{\mathrm{m}}$ & $\Phi_{\mathrm{PSII}}$ & $q_{\mathrm{P}}$ \\
\hline ABA & $116.100 \pm 0.916^{* *}$ & $0.825 \pm 0.001^{*}$ & $0.245 \pm 0.004^{* *}$ & $0.521 \pm 0.003$ \\
BR & $134.533 \pm 2.008^{*}$ & $0.799 \pm 0.005$ & $0.252 \pm 0.002^{* *}$ & $0.615 \pm 0.002^{*}$ \\
CK & $147.300 \pm 1.179$ & $0.754 \pm 0.005$ & $0.154 \pm 0.001$ & $0.518 \pm 0.003$ \\
\hline
\end{tabular}

表中数据为 3 个重复的平均值 \pm 标准误。 ${ }^{*}$ 和 ${ }^{* *}$ 分别表示在 0.01 和 0.05 水平上差异显著。

Each value in the table represents the mean $\pm S E$ of three repetitions. *and ${ }^{* *}$ denote significantly different at the 0.05 and 0.01 probability levels, respectively. 


\section{4 叶绿素和可溶性蛋白含量}

由图 3 和图 4 可见, $\mathrm{ABA}$ 和 $\mathrm{BR}$ 处理后, 用 SPAD-502 测得叶绿素含量比对照高, 在第 7 天分别 高于对照 $5.4 \mathrm{mg} \mathrm{dm}^{2}$ 和 $11.2 \mathrm{mg} \mathrm{dm}^{2}$ 。油菜受冻害后, 叶片中可溶性蛋白含量较低, 喷施生长调节剂后可 溶性蛋白含量均发生了明显的变化, 处理后第 3 天, ABA 处理的叶片中可溶性蛋白含量略低于对照, 而 BR 处理后其含量比对照高 $2.7 \mathrm{mg} \mathrm{g}^{-1} \mathrm{FW}$; 两种植 物生长调节剂处理后第 5 天, 各处理可溶性蛋白含 量均达到最大值, 其中 BR 处理含量最大, 为 57.76 $\mathrm{mg} \mathrm{g}^{-1} \mathrm{FW}$ 。叶片中叶绿素含量和可溶性蛋白含量变 化规律相似，一定浓度的 ABA 和 BR 对冻害后油菜 光合功能的恢复有较明显的促进作用。

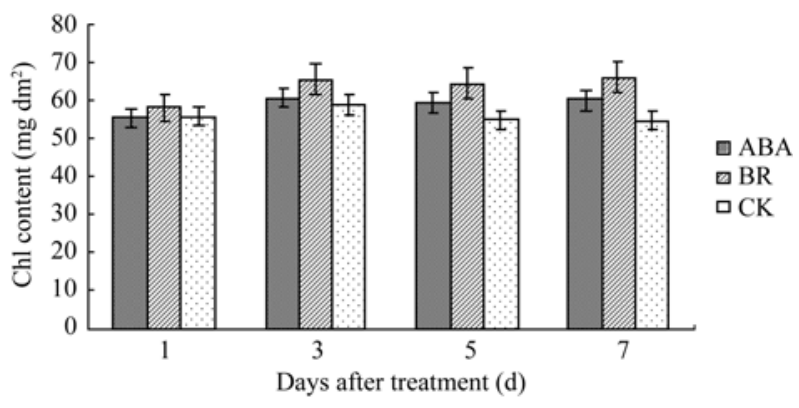

图 3 ABA 和 BR 处理后叶绿素含量的变化(2007-2008)

Fig. 3 Changes of chlorophyll content in short petiole leaves of rapeseed after ABA and BR treatments (2007-2008)

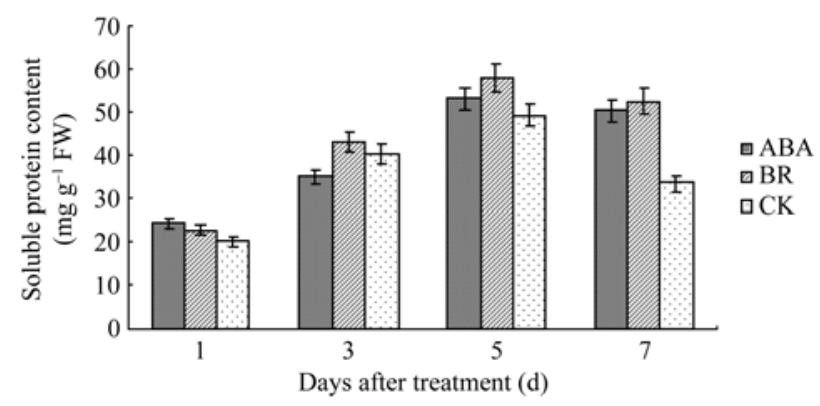

图 4 ABA 和 BR 处理后可溶性蛋白含量的变化 $(2007-2008)$ Fig. 4 Changes of soluble protein content in short petiole leaves of rapeseed after ABA and BR treatments (2007-2008)

\section{5 角果形态的变化}

对角果的定期调查表明(图 5 图 7), 角果长、宽均 在开花后 20 25 d 达到最大值。角果长度在 10 15 d 增长很快, 喷施 $\mathrm{BR} 15 \mathrm{~d}$ 的植株角果长度达到 $6 \mathrm{~cm}$ 以 上, 喷施 $\mathrm{ABA}$ 和对照 $(\mathrm{CK})$ 的角果长度超过 $5 \mathrm{~cm}, 20 \mathrm{~d}$ 后不同处理角果长度约 6.2 7.1 cm, BR 处理后长度最 高, $\mathrm{ABA}$ 处理其次。不同处理的角果宽度在 $15 \mathrm{~d}$ 内从 $0.13 \mathrm{~cm}$ 增至 $0.29 \mathrm{~cm}, 20 \mathrm{~d}$ 后稳定在 $0.43 \sim 0.55 \mathrm{~cm}$ 之间, $\mathrm{ABA}$ 处理后宽度增加, BR 处理后宽度和对照差异不
大。 $\mathrm{BR}$ 处理后主要是增加角果长度, $\mathrm{ABA}$ 处理后角果 变粗, 可见, 生长调节剂对角果长、宽的影响效果不完 全一致。果皮面积在 $10 \mathrm{~d}$ 前约 $2 \mathrm{~cm}^{2}$, 随后快速增长, 20 $\mathrm{d}$ 后稳定在 7.89 9.26 $\mathrm{cm}^{2}$ 之间。

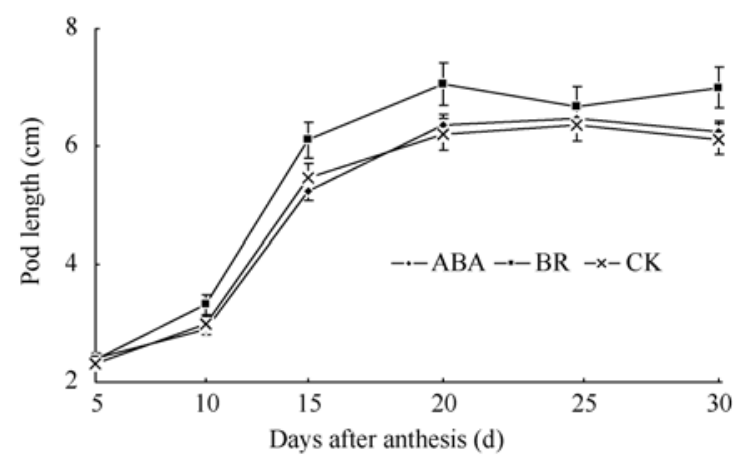

图 5 角果长度的变化 $(2007-2008)$

Fig. 5 Changes of pod length (2007-2008)

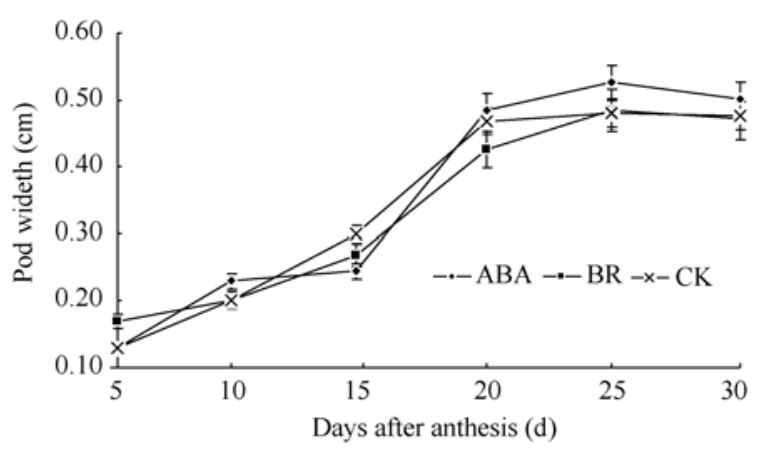

图 6 角果宽度的变化 $(2007-2008)$

Fig. 6 Changes of pod width (2007-2008)

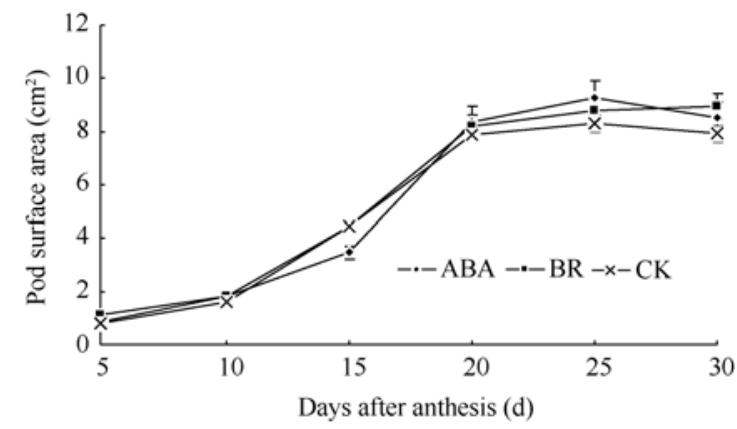

图 7 角果皮面积的变化 $(2007-2008)$

Fig. 7 Changes of pod surface area (2007-2008)

\section{6 产量及产量构成因素}

表 2 显示, 株高比对照降低, 特别是 $\mathrm{ABA}$ 和 $1 \times 10^{-5} \mathrm{~mol} \mathrm{~L}^{-1} \mathrm{BR}$ 处理后株高显著降低。高浓度 $\left(1 \times 10^{-4} \mathrm{~mol} \mathrm{~L}^{-1}\right) \mathrm{ABA}$ 和 $1 \times 10^{-6} \mathrm{~mol} \mathrm{~L}^{-1} \mathrm{BR}$ 处理后一次 有效分枝数增加 1 2 个, 其中 $1 \times 10^{-6} \mathrm{~mol} \mathrm{~L}^{-1} \mathrm{BR}$ 处理 后主花序角果增多，产量构成因素中单株角果数、 每角粒数、千粒重都比对照显著增加，单株产量较 高; 相反的结论是, 由于高浓度 ABA 对顶端优势的 
抑制作用, 其主花序长度、主花序角果数降低, 单株 角果数、每角粒数、千粒重及单株产量都比对照显 著减少。 $76 \times 10^{-6} \mathrm{~mol} \mathrm{~L}^{-1} \mathrm{ABA}$ 处理使每角粒数及千 粒重显著和极显著增加, 单株产量比对照显著提高, $38 \times 10^{-6} \mathrm{~mol} \mathrm{~L}^{-1} \mathrm{ABA}$ 处理也使油菜增产, 但没达到 显著水平。 $2 \times 10^{-6} \mathrm{~mol} \mathrm{~L}^{-1} \mathrm{BR}$ 处理后每角粒数比对 照显著增多, 但喷施高浓度 $\mathrm{BR}\left(1 \times 10^{-5} \mathrm{~mol} \mathrm{~L}^{-1}\right)$ 降 低了产量。

从表 3 可以看出, 喷施 $76 \times 10^{-6} \mathrm{~mol} \mathrm{~L}^{-1} \mathrm{ABA}$ 和
$1 \times 10^{-6} \mathrm{~mol} \mathrm{~L}^{-1} \mathrm{BR}$ 后株高和对照相当，喷施 BR 后一 次有效分枝数比对照增加 1.0 个, 达到显著水平, 主 花序长度和对照相近, 但主花序角果数显著增多, 表明该处理的结角密度增大，产量构成因素中单株 角果数、每角粒数和千粒重显著或极显著上升, 单株 产量比对照显著提高; 喷施 $\mathrm{ABA}$ 后一次有效分枝 数、主花序长度、主花序角果数、单株角果数和对照 差异不显著, 由于每角粒数和千粒重的显著优势, 表 现出比对照显著增产。

表 2 ABA 和 BR 处理对产量及产量构成因素的影响(2006-2007) Table 2 Effects of ABA and BR treatments on yield and yield components (2006-2007)

\begin{tabular}{|c|c|c|c|c|c|c|c|c|}
\hline $\begin{array}{c}\text { 处理 } \\
\text { Treatment }\end{array}$ & $\begin{array}{c}\text { 株高 } \\
\text { Plant height } \\
(\mathrm{cm})\end{array}$ & $\begin{array}{c}\text { 一次有效分枝数 } \\
\text { No. of first } \\
\text { branches per plant }\end{array}$ & $\begin{array}{c}\text { 主花序长度 } \\
\text { Rachis Length }\end{array}$ & $\begin{array}{l}\text { 主花序角果数 } \\
\text { No. of pods in } \\
\text { rachis per plant }\end{array}$ & $\begin{array}{c}\text { 单株有效角 } \\
\text { 果数 } \\
\text { No. of pods } \\
\text { per plant }\end{array}$ & $\begin{array}{l}\text { 每角粒数 } \\
\text { Seeds per } \\
\text { pod }\end{array}$ & $\begin{array}{c}\text { 千粒重 } \\
\text { 1000-seed } \\
\text { weight } \\
\text { (g) }\end{array}$ & $\begin{array}{c}\text { 单株产量 } \\
\text { Plant yield } \\
\text { (g) }\end{array}$ \\
\hline $\operatorname{ABA}\left(38 \times 10^{-6} \mathrm{~mol} \mathrm{~L}^{-1}\right)$ & $201.31^{*}$ & 8.12 & 59.62 & 73.30 & 330.18 & 17.46 & 3.35 & 18.38 \\
\hline $\operatorname{ABA}\left(76 \times 10^{-6} \mathrm{~mol} \mathrm{~L}^{-1}\right)$ & $202.30^{*}$ & 8.43 & 64.98 & 78.20 & 348.67 & $20.37^{* *}$ & $3.42^{*}$ & $21.55^{*}$ \\
\hline $\operatorname{ABA}\left(1 \times 10^{-4} \mathrm{~mol} \mathrm{~L}^{-1}\right)$ & $198.92^{*}$ & $9.60^{*}$ & $49.32^{*}$ & $55.11^{*}$ & $265.31^{*}$ & $15.24^{*}$ & $2.44^{*}$ & $12.48^{*}$ \\
\hline $\mathrm{BR}\left(1 \times 10^{-6} \mathrm{~mol} \mathrm{~L}^{-1}\right)$ & 213.90 & $8.60^{*}$ & 64.30 & $82.73^{*}$ & $367.92^{*}$ & $18.50^{*}$ & $3.82^{*}$ & $20.64^{*}$ \\
\hline $\mathrm{BR}\left(2 \times 10^{-6} \mathrm{~mol} \mathrm{~L}^{-1}\right)$ & 217.00 & 8.35 & 66.45 & 80.34 & 346.52 & $19.43^{*}$ & 3.58 & 18.02 \\
\hline $\mathrm{BR}\left(1 \times 10^{-5} \mathrm{~mol} \mathrm{~L}^{-1}\right)$ & $204.60^{*}$ & 8.40 & 62.50 & 73.87 & 324.50 & 17.39 & 3.04 & 17.54 \\
\hline CK & 218.10 & 7.62 & 61.55 & 72.19 & 328.45 & 17.60 & 3.16 & 17.73 \\
\hline
\end{tabular}

${ }^{*}$ 和 ${ }^{* *}$ 分别表示在 0.05 和 0.01 水平上显著。

* and ${ }^{* *}$ denote significantly different at the 0.05 and 0.01 probability levels, respectively.

表 3 ABA 和 BR 处理对产量及产量构成因素的影响(2007-2008) Table 3 Effects of ABA and BR treatments on yield and yield components (2007-2008)

\begin{tabular}{|c|c|c|c|c|c|c|c|c|}
\hline $\begin{array}{c}\text { 处理 } \\
\text { Treatment }\end{array}$ & $\begin{array}{c}\text { 株高 } \\
\text { Plant height } \\
\text { (cm) }\end{array}$ & $\begin{array}{c}\text { 一次有效分枝数 } \\
\text { No. of first } \\
\text { branches per } \\
\text { plant }\end{array}$ & $\begin{array}{c}\text { 主花序长度 } \\
\text { Rachis } \\
\text { Length }\end{array}$ & $\begin{array}{l}\text { 主花序角果数 } \\
\text { No. of pods in } \\
\text { rachis per plant }\end{array}$ & $\begin{array}{c}\text { 单株有效角 } \\
\text { 果数 } \\
\text { No. of pods } \\
\text { per plant }\end{array}$ & $\begin{array}{c}\text { 每角粒数 } \\
\text { Seeds per } \\
\text { pod }\end{array}$ & $\begin{array}{c}\text { 千粒重 } \\
\text { 1000-seed } \\
\text { weight }\end{array}$ & $\begin{array}{c}\text { 产量 } \\
\text { Yield } \\
\left(\mathrm{kg} \mathrm{hm}^{-2}\right)\end{array}$ \\
\hline $\operatorname{ABA}\left(76 \times 10^{-6} \mathrm{~mol} \mathrm{~L}^{-1}\right)$ & 165.35 & 7.53 & 51.74 & 61.03 & 256.90 & $16.74^{* *}$ & $3.77^{*}$ & $2135.56^{*}$ \\
\hline $\mathrm{BR}\left(1 \times 10^{-6} \mathrm{~mol} \mathrm{~L}^{-1}\right)$ & 168.52 & $8.23^{*}$ & 54.36 & $75.85^{*}$ & $295.43^{*}$ & $16.46^{* *}$ & $3.52^{*}$ & $2067.34^{*}$ \\
\hline $\mathrm{CK}$ & 167.91 & 7.24 & 53.87 & 62.88 & 244.37 & 15.13 & 3.02 & 1874.89 \\
\hline
\end{tabular}

${ }^{*}$ 和 ${ }^{* *}$ 分别表示在 0.05 和 0.01 水平上显著。

${ }^{*}$ and ${ }^{* *}$ denote significantly different at the 0.05 and 0.01 probability levels, respectively.

\section{3 讨 论}

本研究表明, 在油菜始花期喷施不同浓度的植 物生长调节剂, 对光合作用及产量的影响不尽相 同。 $76 \times 10^{-6} \mathrm{~mol} \mathrm{~L}{ }^{-1} \mathrm{ABA}$ 和 $1 \times 10^{-6} \mathrm{~mol} \mathrm{~L}^{-1} \mathrm{BR}$ 能改 善油菜叶片的光合性能, 延缓光合速率的降低, 在 产量构成因素中以提高每角粒数的效果最为显著; 高浓度的 $\mathrm{ABA}$ 和 $\mathrm{BR}$ 对油菜生长产生抑制作用, 特 别是高浓度 $\mathrm{ABA}$ 处理后顶端花序结实较差, 一些幼 嫩的角果脱落, 从而影响了产量。

低温冻害会对油菜的生长造成不利的影响：叶 绿素含量降低, 花青素含量升高, 叶片呈现暗紫色
或青紫色，严重冻害的植株油菜叶柄、叶片呈现玻 璃化, 植株与冰块缠结在一起, 表现为整株严重冻 害; 受损叶片影响油菜光合作用, 直接导致营养供 应不足; 低温使油菜的生长发育延缓, 花期延迟; 油 菜的生物学性状、产量构成因素较低(2008 年冻害调 查资料)。喷施植物生长调节剂 $\mathrm{ABA}$ 和 $\mathrm{BR}$, 能缓解 油菜冻害, 是油菜抗冻减灾的有效栽培技术措施。

油菜冻害后一定浓度的 $\mathrm{ABA}$ 和 $\mathrm{BR}$ 处理较大程 度地增大了冻害后油菜叶片的光合速率和光饱和 点, 促进植株旺盛生长。冻害后 $F_{\mathrm{o}}$ 值较高, 表明 PSII 反应中心已受到不可逆转的失活或破坏, 和前人的 研究结果一致 ${ }^{[22]}$ 。叶片中 PSII 最大光化学量子产量 
$\left(F_{\mathrm{v}} / F_{\mathrm{m}}\right)$ 很低, 表明低温引起 PSII 原初光化学效率减 弱, 但 $\mathrm{ABA}$ 和 $\mathrm{BR}$ 处理后 $F_{\mathrm{v}} / F_{\mathrm{m}}$ 逐渐升高、PSII 实 际的电子传递的量子产量 $\left(\Phi_{\mathrm{PSII}}\right)$ 上升、PSII 电子传递 速率加快、光化学猝灭系数 $\left(q_{\mathrm{P}}\right)$ 增大。推测认为通过 $\mathrm{NPQ}$ 的光合量子效率调节使 $q_{\mathrm{P}}$ 保持恒定, 确保电子 传递速率与 $\mathrm{CO}_{2}$ 的固定速率一致, 从而导致净光合 速率的增加, 有效提高了光能的利用效率 ${ }^{[23]}$ 。叶绿 素是作物进行光合作用的物质基础, 可溶性蛋白含 量是衡量光合功能强弱的一个明显指标 ${ }^{[24-25]}$, 植物 生长调节剂处理提高了叶绿素和可溶性蛋白的含 量, 可能有助于光能捕获 ${ }^{[26]}$ 。

$\mathrm{ABA}$ 和 $\mathrm{BR}$ 处理正值油菜生殖生长旺盛时期, 喷施生长调节剂加速了细胞体积的增大, 促进了细 胞的伸长、分裂和器官的分化 ${ }^{[27]}$, 其效应影响到角 果的形成, 使角果皮面积增加。 $\mathrm{BR}$ 和 $\mathrm{ABA}$ 处理分 别导致角果增长、增粗, 所以二者促进油菜发育的 机理可能不一样。油菜成熟期间光合作用主要依靠 角果皮, 绿色角果皮能提供给籽粒 $2 / 3$ 的干物质 ${ }^{[28]}$, 较大的角果皮能积累更多的光合产物, 这些光合产 物向籽粒大量运输, 使每角粒数和千粒重都显著高 于对照。单株角果数是构成油菜产量的重要因素之 一, 油菜获得高产的关键是具有足够数量的角果以 及空间分布合理的结角层, 并使每个角果有足够的 受光量, 使群体有高的光合生产力 ${ }^{[29]}$ 。植物生长调 节剂处理后单株角果数增加, 另外也观察到植株形 态发生改变, 分枝挺立, 角果在植株上排列紧凑又 彼此不遮盖, 这样的株型有利于角果有效吸收光能, 增强光合作用，提高产量。

外源 $\mathrm{ABA}$ 在植物抗低温胁迫中起重要的调节作 用。近年来的研究认为, 低温诱导植物内源 $\mathrm{ABA}$ 的

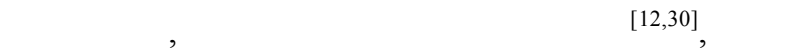
$\mathrm{ABA}$ 和 $\mathrm{BR}$ 处理受冻油菜后, 植株内源 $\mathrm{ABA}$ 水平的 变化, 本文没有涉及。外源 $\mathrm{ABA}$ 通过增强膜的稳定 性和过氧化氢酶的活性, 诱导合成甜菜碱及抗坏血 酸等, 使植株产生抗寒性 ${ }^{[1-32]}$ 。冻害后喷施 $\mathrm{ABA}$ 和 $B R$, 能调节油菜的生理功能, 但低温下油菜植株内 源激素的变化规律, 喷施 $\mathrm{ABA}$ 和 $\mathrm{BR}$ 后生长调节剂 受体、生长调节剂感受和信号传导途径, 生长调节剂 对基因表达的调控, 基因信息及功能分析等有待继 续研究。

\section{4 结论}

油菜始花期喷施 $76 \times 10^{-6} \mathrm{~mol} \mathrm{~L}{ }^{-1} \mathrm{ABA}$ 和 $1 \times 10^{-6}$ mol L $\mathrm{L}^{-1} \mathrm{BR}$ 能提高叶片光合速率和产量, 油菜冻害 后喷施该浓度的 $\mathrm{ABA}$ 和 $\mathrm{BR}$, 叶片光饱和点增加, 叶绿素苂光参数中 $F_{\mathrm{v}} / F_{\mathrm{m}} 、 \Phi_{\mathrm{PSII}}$ 和 $q_{\mathrm{P}}$ 等增加, $F_{\mathrm{o}}$ 和 NPQ 值降低, 叶绿素和可溶性蛋白的含量升高。 $\mathrm{ABA}$ 和 BR 处理都能增加油菜的角果大小、单株有 效角果数、每角粒数及千粒重及产量, 尤以增加每 角粒数的效果最为明显。植物生长调节剂处理是促 进油菜生长和缓解冻害的有效措施。

\section{References}

[1] Lü J(吕军), Wang B-L(王伯伦), Meng W-R(孟维韧), Zhao F-Y(赵凤艳). The characteristics of photosynthesis and dry matter production in Japonica rice cultivars with different type panicles. Sci Agric Sin (中国农业科学), 2007，40(5)：902-908(in Chinese with English abstract)

[2] Levitt J. Responses of Plants to Environmental Stresses: Chilling, Freezing, and High Temperature Stresses, 2nd edn. Vol. 1. New York: Academic Press, 1980. pp 365-434

[3] Jian L-C(简令成). Advances of the studies on the mechanism of plant cold hardiness. Chin Bull Bot (植物学通报), 1992, 9(3): 17-22(in Chinese with English abstract)

[4] Grafflage S, Krause G H. Simulation of in situ freezing damage of the photosynthetic apparatus by freezing in vitro of thylakoids suspended in complex media. Planta, 1986, 168: 67-76

[5] Hetherington S E, He J, Smillie R M. Photoinhibition at low temperature in chilling-sensitive and -resistant plants. Plant Physiol, 1989, 90: 1609-1615

[6] Li X-G(李新国), Duan W(段伟). PSI photoinhibition under low temperature. Plant Physiol Commun (植物生理学通讯), 2002, 38(4): 375-381(in Chinese)

[7] Bilger W, Björkman O. Role of the xanthophyll cycle in photoprotection elucidated by measurements of light-induced absorbance changes, fluorescence and photosynthesis in leaves of Hedera canariensis. Photosynth Res, 1990, 25: 173-186

[8] Yang J-C(杨建昌), Wang Z-Q(王志琴), Zhu Q-S(朱庆森), Su B-L(苏宝林). Regulation of ABA and GA to the grain filling rice. Acta Agron Sin (作物学报), 1999, 25(3): 341-348(in Chinese with English abstract)

[9] Yang J-C(杨建昌), Chang E-H(常二华), Zhang W-J(张文 杰), Wang Z-Q(王志琴), Liu L-J(刘立军). Relationship between root chemical signals and grain quality of rice. $\mathrm{Sci}$ Agric Sin (中国农业科学), 2006, 39(1): 38-47(in Chinese with English abstract)

[10] Guan C-Y(官春云), Huang T-P(黄太平)，Li X(李栒)，Chen $\mathrm{S}-\mathrm{Y}$ (陈社员). Effect of different hormones on siliques growth and seeds maturity in rapeseed (B. napus). Chin J Oil Crop Sci (中国油 料作物学报), 2004, 26 (1): 5-7(in Chinese with English abstract)

[11] Tan Z-B(谭振波), Liu X(刘昕), Cao M-Q(曹鸣庆). Recent advances on mechanisms of maize chilling tolerance. J Maize Sci (玉 
米科学), 2002, 10(2): 56-60(in Chinese with English abstract)

[12] Nayyara H, Bainsb T S, Kumara S. Chilling stressed chickpea seedlings: Effect of cold acclimation, calcium and abscisic acid on cryoprotective solutes and oxidative damage. Environ Exp Bot, 2005, 54: 275-285

[13] Zhou Q(周琴), Sun X-F(孙小芳), Guo Y-L(郭月玲), Jiang H-D(江海东). Effects of 6-BA and PP333 on the ability of freezing tolerance of oil rape (Brassica napus) seeding. Chin J Oil Crop Sci (中国油料作物学报), 2007, 29(3): 286-290(in Chinese with English abstract)

[14] Zhang X-K(张学昆), Zhang C-L(张春雷), Liao X(廖星), Wang H-Z(王汉中). Investigation on 2008' low temperature and freeze injure on winter rape along Yangtze River. Chin J Oil Crop Sci (中国油料作物学报), 2008, 30(1): 122-126(in Chinese with English abstract)

[15] Aroca R, Vernieri P, Irigoyen J J, Sanchez-Diaz M, Tognoni F, Pardossi A. Involvement of abscisic acid in leaf and root of maize (Zea mays L.) in avoiding chilling induced water stress. Plant Sci, 2003, 165: 671-679

[16] Liu R-X(刘瑞显), Wang Y-H(王友华), Chen B-L(陈兵林), Guo W-Q(郭文琦), Zhou Z-G(周治国). Effects of nitrogen levels on photosynthesis and chlorophyll fluorescence characteristics under drought stress in cotton flowering and boll forming stage. Acta Agron Sin (作物学报), 2008, 34(4): 675-683(in Chinese with English abstract)

[17] Wang X-K(王学奎). Principles and Techniques of Plant Physiological Biochemical Experiment (植物生理生化实验原理和技 术), 2nd edn. Beijing: Higher Education Press, 2006. pp 190-192(in Chinese)

[18] Clark J M. The effect of leaf removal on yield components of Brassica napus. Can J Plant Sci, 1978, 58: 1103-1105

[19] Xiang B(项斌), Lin S-H(林舜华), Gao L-M(高雷明). Responses to doubled $\mathrm{CO}_{2}$ in Medicago sativa: Studies on ecophysiology and simulation modeling. Acta Bot Sin (植物学报), 1996, 38(1): 62-71(in Chinese with English abstract)

[20] Guo L-W(郭连旺), Shen Y-G(沈允钢). Protective mechanisms against photodamage in photosynthetic apparatus of higher plants. Plant Physiol Commun (植物生理学通讯), 1996, 32(1): 1-8(in Chinese with English abstract)

[21] Genty B, Briantais J M, Baker N R. The relationship between the quantum yield of photosynthetic electron transport and quenching of chlorophyll fluorescence. Biochim Biophys Acta, 1989, 990: 87-92

[22] Schreiber U, Aromond S U. Heat-induced changes of chlorophyll fluorescence in isolated chloroplasts and related heat-damage at the pigment level. Biochim Biophys Acta, 1987, 502: 138-151

[23] Maxwell K, Johnson G N. Chlorophyll fluorescence: A practical guide. $J$ Exp Bot, 2000, 51: 659-668

[24] Huang X-Q(黄雪青), Jiao D-M(焦德茂), Li X(李霞). Characteristics of chlorophyll fluorescence and membrane-lipid peroxidation of various high-yield rice under photooxidation conditions. Acta Bot Sin (植物学报), 2002, 44(3): 279-286(in Chinese with English abstract)

[25] Robert D R, Thompson J E, Dmberff E B. Differential changes in the synthesis and steady-levels of thyokoid protein during bean leaf senescence. Plant Mol Biol, 1987, 9: 343-353

[26] Peng C L, Lin Z F, Lin G Z, Chen S W. The anti-photoxidation of anthocyanins-rich leaves of a purple rice cultivar. Sci China (Ser C), 2006, 36(3): 209-216

[27] Hou L-P(侯雷平), Li M-L(李梅兰). Progress of studies on the plant growth promoting mechanism of Brassinolide (BR). Chin Bull Bot (植物学通报), 2001，18(5): 560-566(in Chinese with English abstract)

[28] Leng S-H(冷锁虎), Zhu G-R(朱耕如), Deng X-L(邓秀兰). Studies on the sources of the dry matter in the seed of rapeseed. Acta Agron Sin (作物学报), 1992, 18(4): 250-258(in Chinese with English abstract)

[29] Leng S-H(冷锁虎), Zuo Q-S(左青松), Dai J(戴敬), Yu Y-Z(喻义 珠). Studies on indices of high yield population quality of rapeseed. Chin J Oil Crop Sci (中国油料作物学报), 2004, 26 (4): 38-45(in Chinese with English abstract)

[30] Chandler P M, Robertson M. Gene expression regulated by abscisic acid and its relation to stress tolerance. Annu Rev Plant Physiol Pant Mol Biol, 1994, 45: 113-141

[31] Nayyar H, Kaushal S K. Chilling induced oxidative stress in germinating wheat grains as affected by water stress and calcium. Biol Plant, 2002, 45: 601-604

[32] Xing W, Rajashekar C B. Glycine betaine involvement in freezing tolerance and water stress in Arabidopsis thaliana. Environ Exp Bot, 2001, 46: 21-28 